\title{
A Rectangular Planar Spiral Antenna for GIS Partial Discharge Detection
}

\author{
Xiaoxing Zhang, ${ }^{1}$ Yefei Han, ${ }^{1}$ Wei Li, ${ }^{2}$ and Xuetao Duan ${ }^{2}$ \\ ${ }^{1}$ State Key Laboratory of Power Transmission Equipment \& System Security and New Technology, \\ Chongqing University, Chongqing 400044, China \\ ${ }^{2}$ Xinjiang Electric Power Research Institute, High-Tech Industrial Development Zone, Urumqi 830000, China
}

Correspondence should be addressed to Xiaoxing Zhang; xiaoxing.zhang@outlook.com

Received 5 March 2014; Revised 3 May 2014; Accepted 11 May 2014; Published 5 June 2014

Academic Editor: Wenxing Li

Copyright (C) 2014 Xiaoxing Zhang et al. This is an open access article distributed under the Creative Commons Attribution License, which permits unrestricted use, distribution, and reproduction in any medium, provided the original work is properly cited.

\begin{abstract}
A rectangular planar spiral antenna sensor was designed for detecting the partial discharge in gas insulation substations (GIS). It can expediently receive electromagnetic waves leaked from basin-type insulators and can effectively suppress low frequency electromagnetic interference from the surrounding environment. Certain effective techniques such as rectangular spiral structure, bow-tie loading, and back cavity structure optimization during the antenna design process can miniaturize antenna size and optimize voltage standing wave ratio (VSWR) characteristics. Model calculation and experimental data measured in the laboratory show that the antenna possesses a good radiating performance and a multiband property when working in the ultrahigh frequency (UHF) band. A comparative study between characteristics of the designed antenna and the existing quasi-TEM horn antenna was made. Based on the GIS defect simulation equipment in the laboratory, partial discharge signals were detected by the designed antenna, the available quasi-TEM horn antenna, and the microstrip patch antenna, and the measurement results were compared.
\end{abstract}

\section{Introduction}

Partial discharge signal has been widely studied as an important indicator for characterizing the merits of GIS insulation performance [1]. Electrical monitoring methods include the pulse current method and the UHF method. The UHF method detects high frequency electromagnetic signals $(300 \mathrm{MHz}-3 \mathrm{GHz})$ excited by partial discharge in the airspace. Numerous interfering signals can be effectively avoided. The UHF method is suitable for online monitoring for its high frequency, wide bandwidth, and high sensitivity. Through UHF signals, not only can the presence of defects in GIS be detected, but the occurrence and severity of the insulation fault can also be determined [2].

Currently, the antenna sensor of GIS partial discharge monitoring is mainly divided into two types, namely, the built-in sensor and the external sensor [3]. The built-in sensor is placed internally in the GIS and it must be considered during the design of GIS equipment to reduce its additional effect on the internal electric field. Its advantages are high sensitivity, very good detection results, and strong antiinterference ability $[4,5]$. The external sensor is mainly used in GIS equipment that has been put into operation and has no built-in sensors. It is installed on the basin insulator and is able to test the insulation condition of GIS through collecting leakage electromagnetic waves from partial discharge. The advantage is easy installation and maintenance and the electric field inside the device remains unaffected [6-8]. To carry out the UHF detection method smoothly, the designed antenna should meet the development trend of miniaturization and broadband, taking into account the bandwidth and gain of the sensor. Thus, the antenna will receive more partial discharge signals. A new type of planar helical antenna sensor for detecting the UHF of GIS partial discharge was developed in our lab. The designed antenna has a small volume and wide frequency band. Through simulation and experimental analysis for its parameter, the designed antenna can effectively detect UHF signal and satisfy the requirement of GIS online monitoring. 


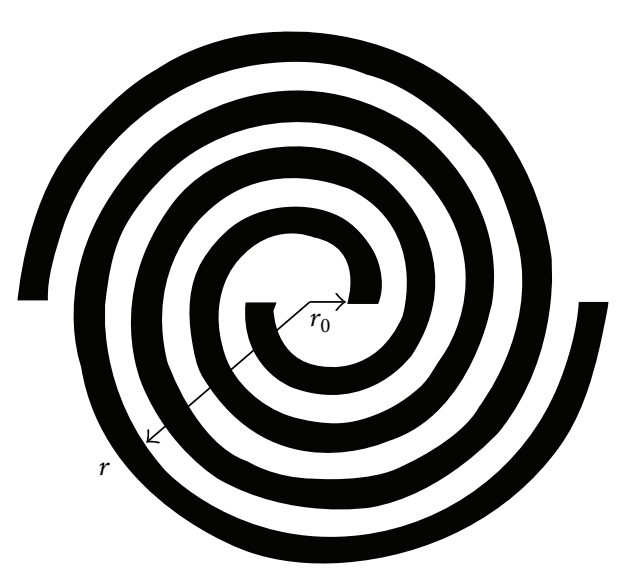

(a)

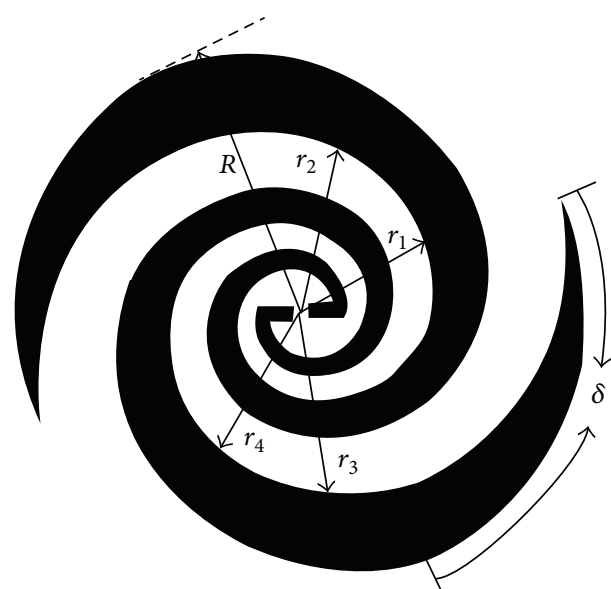

(b)

Figure 1: Planar spiral antenna.

\section{The Basic Form of the Helical Antenna}

The helical antenna is made of metal with good electrical conductivity and has a spiral shape [9]. It has the advantage of circular polarization and broad beam width; thus, it is widely used in satellite communications and personal mobile communications $[10,11]$. Helical antennas can be divided into three-dimensional helical antennas and plane helical antennas according to their structure. The basic form of the planar helical antenna consists of an Archimedes helical antenna and an equiangular helical antenna. The radius of the Archimedean helical antenna increases as the angle increases. Its curve equation is

$$
r=r_{0}+a \phi,
$$

where $r_{0}$ is the initial radius, $a$ is the spiral growth, and $\varphi$ is the angle in radians.

A double-arm Archimedean helical antenna $[12,13]$ is shown in Figure 1(a). The antenna generally uses the balance feed at the center of the spiral surface, and the main radiation area is focused on the average circumference of a wavelength band, also known as the effective radiative zone. When the frequency changes, the effective radiative zone changes as well, but the radiation pattern basically remains unchanged. Moreover, when the effective radiative zone for the antenna is at the outermost region, its frequency is at the lowest operating frequency of the antenna. For the circular spiral surface, the perimeter is $C=\pi \times D=\lambda_{\text {max }}$, such that the outer diameter of the antennas is the following:

$$
D=\frac{\lambda_{\max }}{\pi} .
$$

Since the planar Archimedean helical antenna was proposed in the 1950s, due to its features such as broadband, circular polarization, and low profile, it has received an increasing amount of attention and application.

The equation of the planar equiangular helical antenna is as follows:

$$
r=r_{0} e^{a\left(\phi-\phi_{0}\right)},
$$

where $\varphi_{0}$ is the initial radius, $a$ is the spiral growth, and $r_{0}$ is the radius vector corresponding to $\varphi_{0}$. A planar equiangular helical antenna [14] is shown in Figure 1(b).

\section{Characteristics of the Rectangular Plan Spiral Antenna}

\subsection{Antenna Structure}

(a) Design of Rectangular Spiral. The rectangular spiral structure is a variation of the Archimedes spiral structure. It has the same advantages as the Archimedes spiral structure. Furthermore, it has a more simple structure and higher space utilization. Therefore, the designed helical antenna in this paper uses a planar rectangular spiral structure. A rectangular spiral structure effectively reduces antenna size and weight. It also facilitates manufacturing.

(b) Reflecting Cavity and Shielding. Planar spiral antennas have the characteristics of wide bandwidth, small volume, wide main lobe circular polarization, and normal two-way radiation. However, antennas require unidirectional radiation. Therefore, the overall structure of the antenna designed in this paper is the semienclosed planar spiral antenna. The antenna surface, except for the receiving surface, is shielded by a metal shield cavity. A reflecting cavity is also added. Furthermore, the antenna should be filled with wave absorption material to ensure wide bandwidth.

(c) Bow-Tie Vibrator Loading. To increase the bandwidth, the terminal of the spiral selects the bow-tie vibrator loading (Figure 2) to reduce the transmission loss of the spiral periphery. The bow-tie antenna is a low-profile structure planar antenna. It has the advantages of being lightweight and easy to install [15]. The performance of the antenna is determined by two main factors: opening angle $\theta_{0}$ and arm length $l$ (Figure 3). The larger the opening angle is, the wider the frequency band of operation is. However, the lateral dimension of the antenna will increase if the opening 


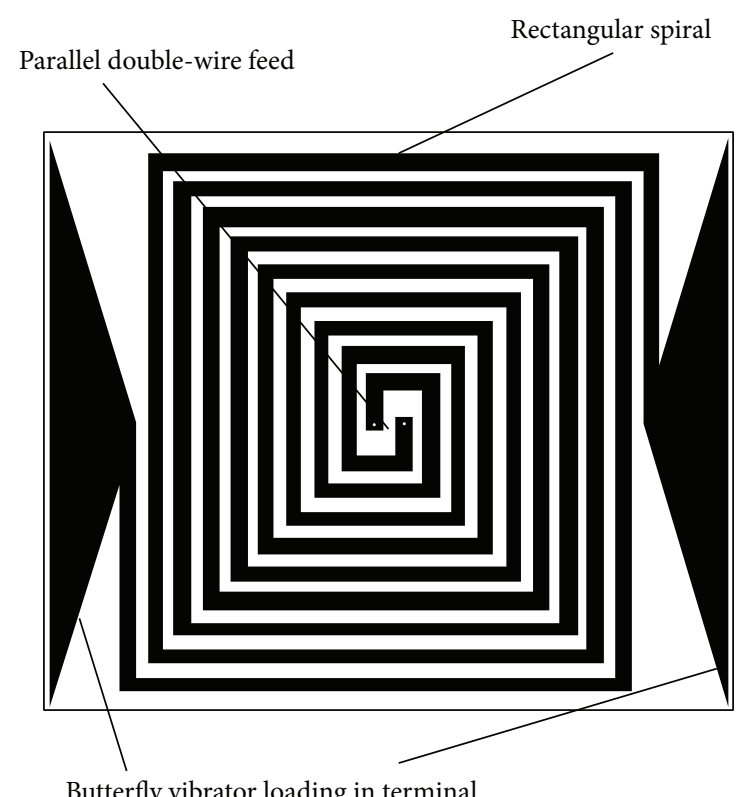

Butterfly vibrator loading in terminal

Figure 2: The structure of the planar spiral antenna.

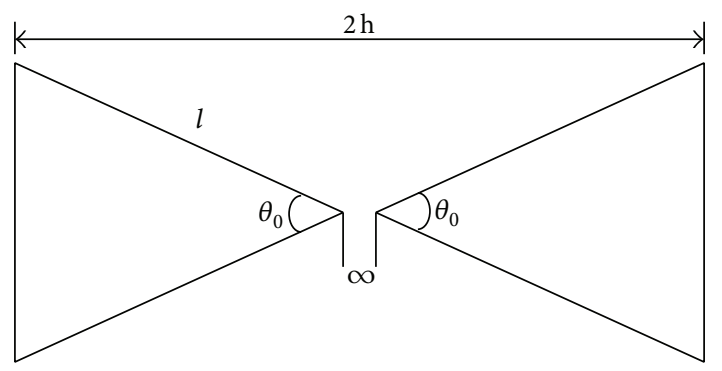

Figure 3: The structure of the bow-tie antenna.

angle is too large. Miniaturization of the antenna cannot be guaranteed. The arm length of the antenna metal vibrator is an important parameter for determining the low-end frequencies of the input impedance bandwidth of the antenna. The longer the $\operatorname{arm} l$, the better the low-frequency covering performance of the antenna. The work of the antenna signal is a Gaussian pulse radiation for their fidelity waveform. Thus, the radiation waveform fidelity will be higher for antennas whose working signal is a Gaussian pulse. According to the empirical formula, bow-tie antenna arm length and the corresponding wavelength under low frequency satisfy the following relationship:

$$
l=\frac{\lambda}{4}\left(1-\frac{97.82}{Z_{c}}\right)
$$

where $\lambda$ is the corresponding wavelength under the low-end frequency of the antenna input impedance bandwidth and $Z_{c}$ is the characteristic impedance of the antenna, which is given as follows:

$$
Z_{c}=120 \ln \left(\operatorname{ctg}\left(\frac{\theta_{0}}{4}\right)\right)
$$

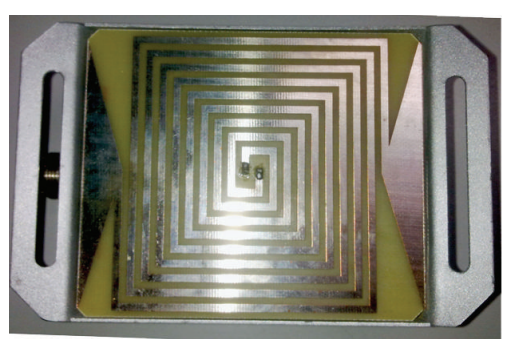

FIgURE 4: Physical map of the designed antenna.

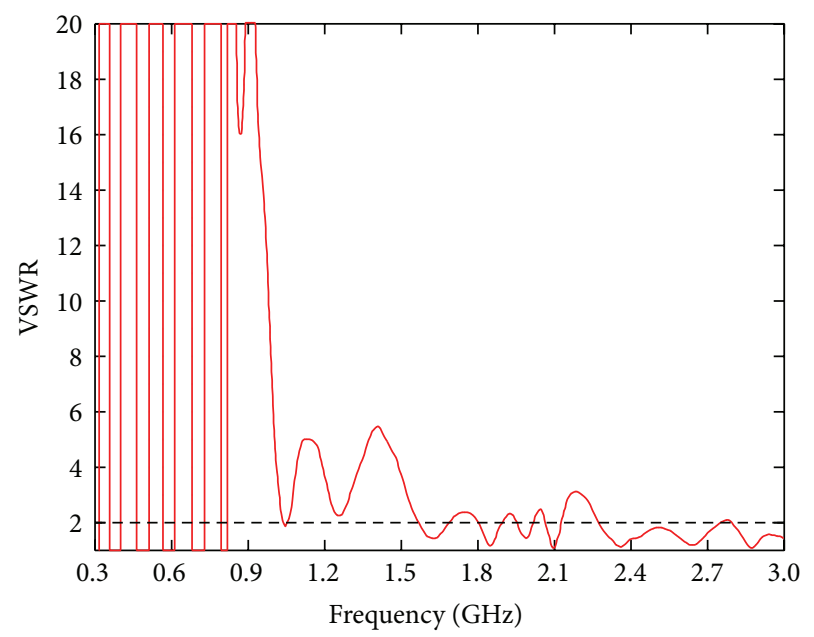

FIGURE 5: VSWR with a frequency between $300 \mathrm{MHz}$ and $3 \mathrm{GHz}$.

The bow-tie antenna and the equiangular spiral antenna are both wideband antennas. Wideband antenna can achieve broadband impedance matching and reduce transmission loss after taking loading mode, thereby improving the radiation characteristics of the antenna.

Figure 4 shows a physical map of the rectangular spiral antenna designed in this paper. The size of the antenna is $132 \times$ $85 \times 50 \mathrm{~mm}$ and its weight is $278 \mathrm{~g}$.

3.2. Antenna VSWR. VSWR is the reciprocal of the traveling wave coefficients. Its value is from 1 to infinity. VSWR is widely used in engineering to indicate the degree of impedance mismatch between antenna impedance and transmission line impedance. The VSWR ratio simulation results of the designed antenna are shown in Figure 5. The figure shows that VSWR is less than 2 within 1.6 $\mathrm{GHz}-2.1 \mathrm{GHz}$ and $2.3 \mathrm{GHz}-3.0 \mathrm{GHz}$, with a wide frequency range.

In many cases, the antenna impedance is unknown but the VSWR can be measured. Thus, the mold of the reflection coefficient can be calculated using VSWR. The measured VSWR is shown in Figure 6. Figure 6 shows that the VSWR is better within $1.15 \mathrm{GHz}-1.55 \mathrm{GHz}, 1.9 \mathrm{GHz}-2.7 \mathrm{GHz}$, and $2.85 \mathrm{GHz}-3 \mathrm{GHz}$, whereas the VSWR is poor below $1 \mathrm{GHz}$. The simulation results of VSWR are basically consistent with the measurements. 


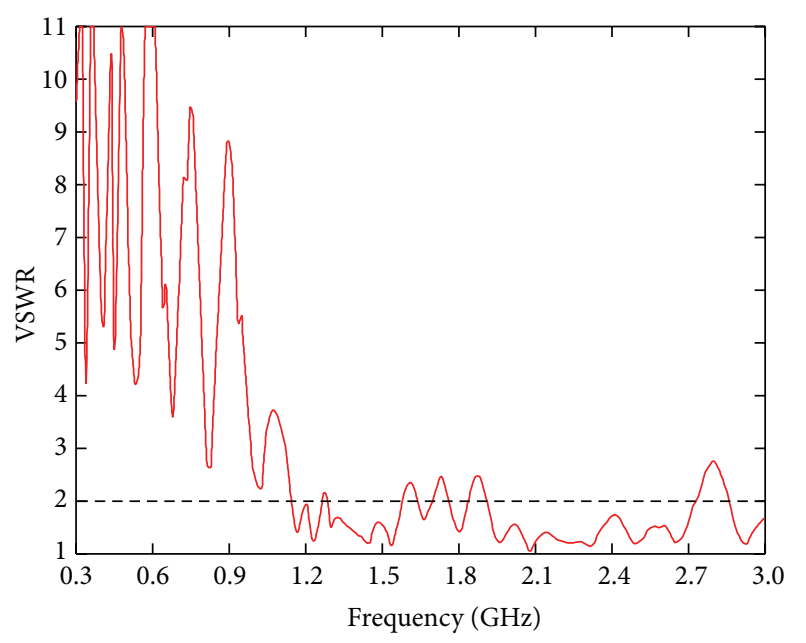

FIGURE 6: Measured VSWR of the designed antenna.

TABLE 1: Measured gain of the designed antenna.

\begin{tabular}{lccccccc}
\hline Frequency (MHz) & 300 & 500 & 800 & 1000 & 1500 & 2000 & 3000 \\
Gain $(\mathrm{dB})$ & -36 & -23 & -9 & 2.5 & 4.5 & 5.5 & 11.7 \\
\hline
\end{tabular}

TABLE 2: The value of the designed antenna pattern.

\begin{tabular}{lccc}
\hline $\begin{array}{l}\text { Frequency } \\
(\mathrm{MHz})\end{array}$ & $\begin{array}{c}\text { Main lobe } \\
\text { width }(\mathrm{dB})\end{array}$ & $\begin{array}{c}\text { Beamwidth } \\
3 \mathrm{~dB}(\mathrm{deg})\end{array}$ & $\begin{array}{c}\text { Side-lobe } \\
\text { level }(\mathrm{dB})\end{array}$ \\
\hline 500 & -24.5 & & \\
1000 & 2.9 & 105.8 & -4.5 \\
1500 & 4.6 & 101.7 & -9.0 \\
2000 & 6.7 & 89.9 & -8.2 \\
2500 & 7.7 & 78.1 & -14.6 \\
3000 & 8.5 & 74.1 & -17.9 \\
\hline
\end{tabular}

3.3. Gain of the Antenna. The measured results of the antenna gain are shown in Table 1. As the frequency increases, the antenna gain increases. The antenna gain achieves $11.7 \mathrm{~dB}$ when the frequency is $3000 \mathrm{MHz}$.

3.4. Antenna Patterns. The helical antenna has characteristics of axial rotational symmetry. Thus, only the circularly polarized antenna pattern on the horizontal direction from $500 \mathrm{MHz}$ to $3 \mathrm{GHz}$ was tested. The designed antenna patterns under several specific frequencies are shown in Figure 7. The corresponding parameters are shown in Table 2. The main lobe width is the angle between two radius vectors in the main lobe when the antenna radiation power is half of maximum value. It is used to indicate the concentration degree of antenna power radiation. The smaller the main lobe width and the sharper the antenna pattern, the more concentrated the antenna radiation. Figure 9 and Table 2 show that the gain of the antenna exhibits a rising trend as the frequency increases. Furthermore, the antenna achieves a good directional radiation characteristic in the full-band.
TABLE 3: Measured gain of the quasi-TEM horn antenna.

\begin{tabular}{lcccccc}
\hline Frequency $(\mathrm{MHz})$ & 500 & 800 & 1000 & 1500 & 2000 & 3000 \\
Gain $(\mathrm{dB})$ & -12.6 & -1.4 & 1.3 & 3.2 & 5.1 & 3.8 \\
\hline
\end{tabular}

\section{Comparative Study of Rectangular Plane Spiral Antenna}

4.1. Comparative Study of Antenna Characteristics. External sensors which have been used to detect GIS partial discharge in our laboratory have two types: the quasi-TEM horn antenna [16] and the microstrip patch antenna [17].Structure of the quasihorn antenna is shown in Figure 8; its size is $129 \mathrm{~mm} \times 90 \mathrm{~mm} \times 60 \mathrm{~mm}$ and its weight is $920 \mathrm{~g}$. The size of the rectangular spiral antenna is about $4 / 5$ of the quasiTEM horn antenna and $1 / 3$ of its weight. The physical map of the microstrip patch antenna is shown in Figure 9; its size is $261 \times 142 \times 112 \mathrm{~mm}$ and its weight is $1040 \mathrm{~g}$. The rectangular spiral antenna size is much smaller than the microstrip patch antenna. Its size is only $1 / 7$ of the microstrip patch antenna and its weight is only $1 / 4$ of that. In brief, the rectangular spiral antenna is much smaller and lighter, thus facilitating the installation.

The rectangular spiral antenna has almost the same size as the quasi-TEM horn antenna, so the paper mainly makes a comparative analysis for some characteristics of these two antennas. The measured VSWR of a quasihorn antenna is shown in Figure 10. Figure 10 shows that the quasihorn antenna has an ideal VSWR within $820 \mathrm{MHz}-930 \mathrm{MHz}, 1.25 \mathrm{GHz}-1.65 \mathrm{GHz}, 2.15 \mathrm{GHz}-2.3 \mathrm{GHz}$, and $2.85 \mathrm{GHz}-3 \mathrm{GHz}$. It is obvious that the rectangular spiral antenna has a wider frequency band compared to the quasiTEM horn antenna. Table 3 shows the measured gain of the quasi-TEM horn antenna. Compared to Table 3 and Table 1, gain of the rectangular spiral antenna is overall better than the quasi-TEM horn antenna above $1 \mathrm{GHz}$, whereas the gain is worse below $800 \mathrm{MHz}$. The microstrip patch antenna band is $340 \mathrm{MHz}-440 \mathrm{MHz}$ and the measured maximum gain is $5.38 \mathrm{~dB}$. Its frequency band range and maximum gain values are all inferior to the rectangular spiral antenna.

4.2. Comparative Study of Partial Discharge Measurements. To verify the measurement results of the designed antenna, a needle-plate electrode was used to simulate metal protrusion defects of GIS and partial discharge tests were carried out. Figures 8 and 11 show the experimental circuit of partial discharge in the lab. The designed antenna was used to collect partial discharge signals. Then the measured results are compared with the signals collected using a quasi-TEM horn antenna and a microstrip patch antenna. A high-speed digital oscilloscope (Tektronix Oscilloscope 7104: bandwidth is $1 \mathrm{GHz}$, the maximum sampling rate is $20 \mathrm{GS} / \mathrm{s}$, and memory depth is $48 \mathrm{M}$ ) was used to record waveforms.

When the needle-plate electrode is added to $9 \mathrm{kV}$, the partial discharge signals are received from the rectangular spiral antenna and the quasi-TEM horn antenna simultaneously, as Figure 12 shows. The red waveform was measured using the rectangular spiral antenna with a maximum amplitude of 


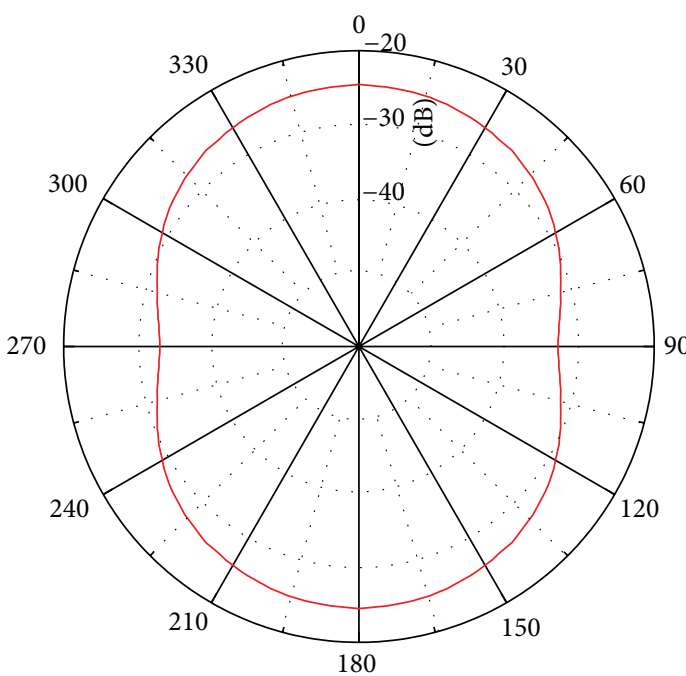

(a) $\mathrm{f}=500 \mathrm{MHz}$

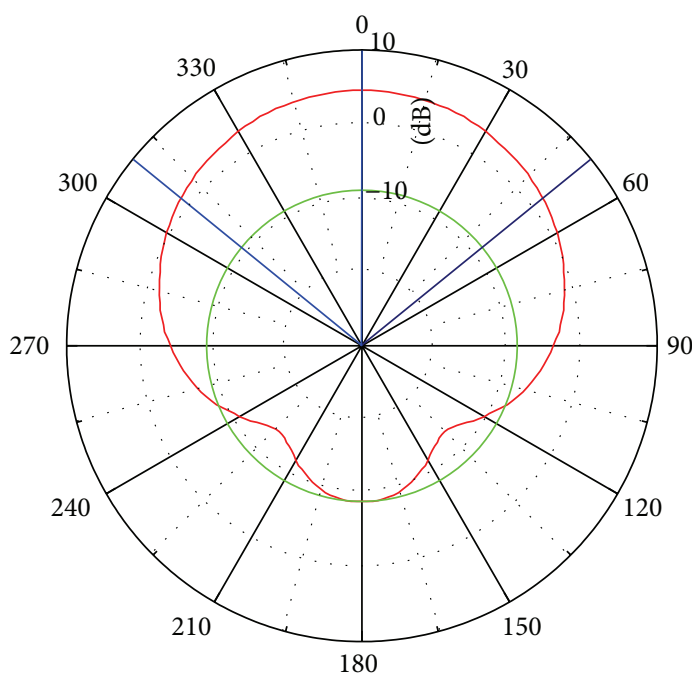

(c) $\mathrm{f}=1500 \mathrm{MHz}$

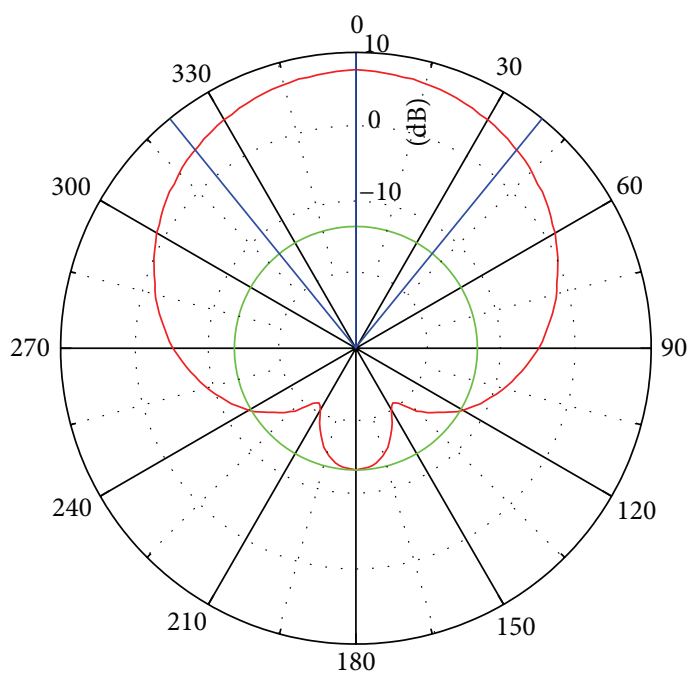

(e) $\mathrm{f}=2500 \mathrm{MHz}$

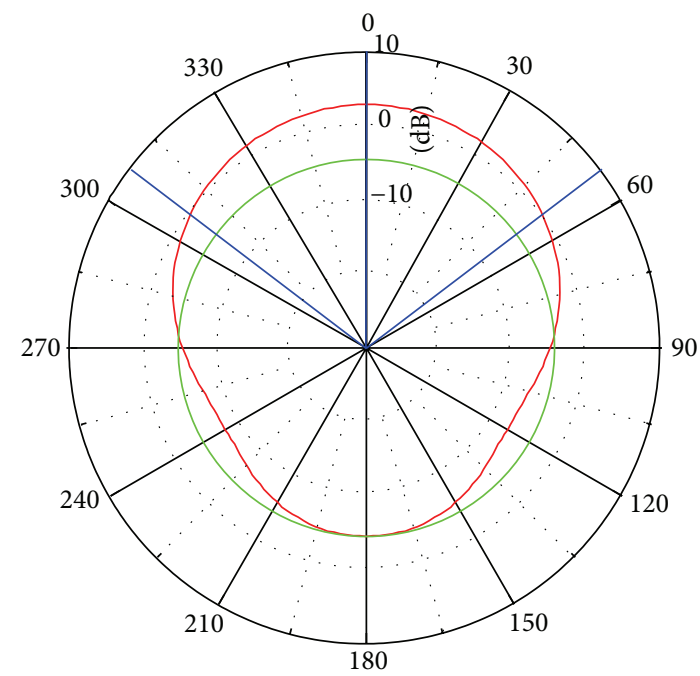

(b) $\mathrm{f}=1000 \mathrm{MHz}$

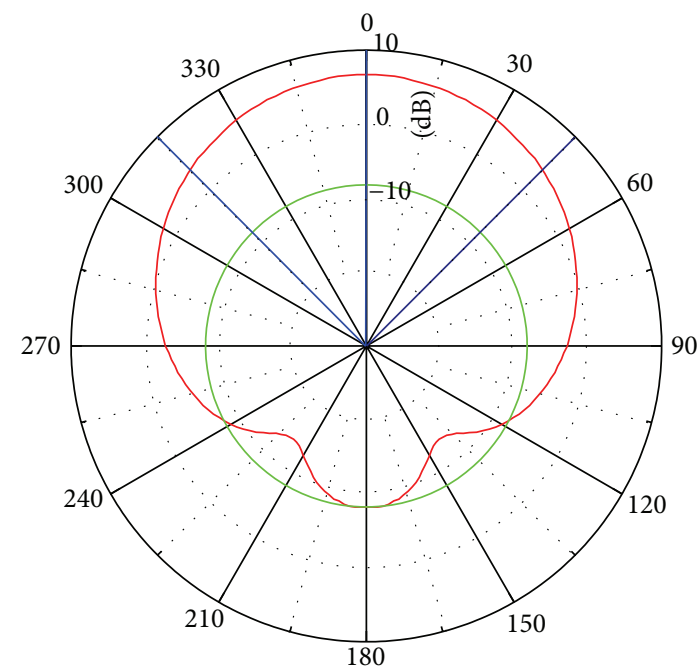

(d) $\mathrm{f}=2000 \mathrm{MHz}$

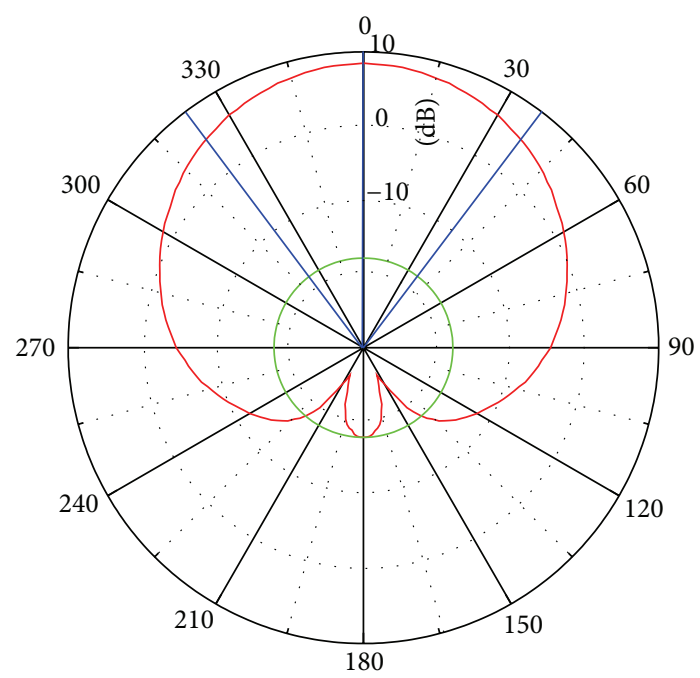

(f) $\mathrm{f}=3000 \mathrm{MHz}$

FIgURE 7: The designed antenna pattern. 

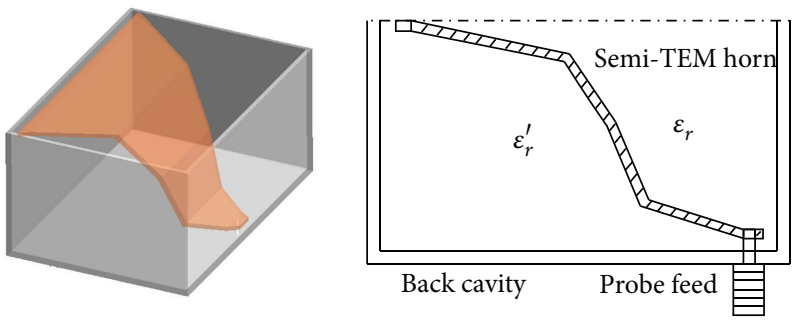

FIGURE 8: Structure of the quasi-TEM horn antenna.

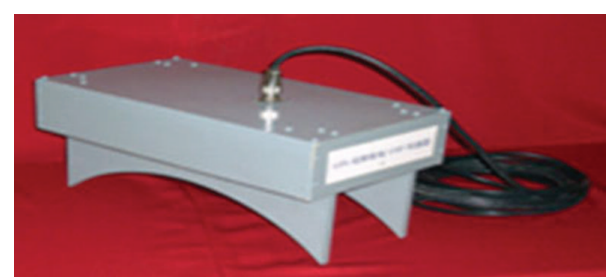

Figure 9: Physical map of the microstrip patch antenna.

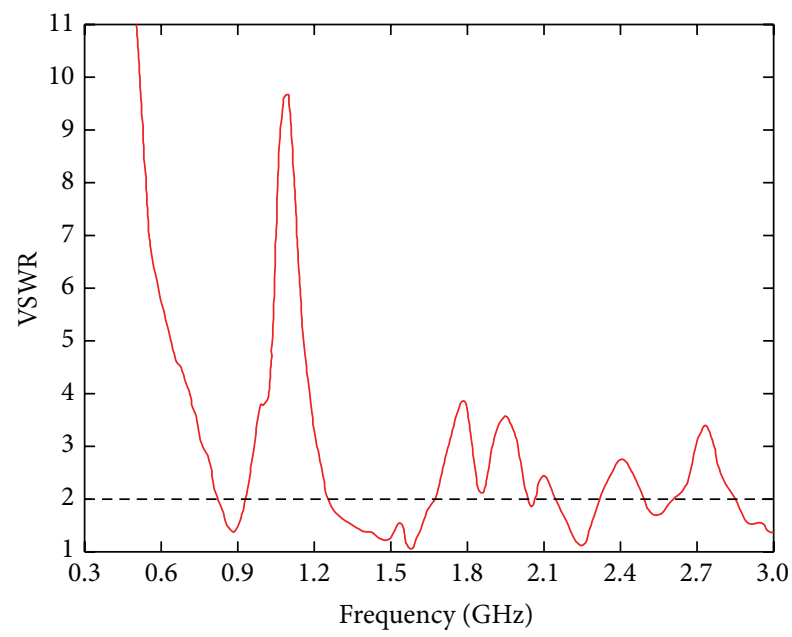

FIGURE 10: Measured VSWR of the quasi-TEM horn antenna.

10.2 $\mathrm{mV}$. The green waveform was measured using a quasiTEM horn antenna with a maximum amplitude of $10.6 \mathrm{mV}$. Figure 13 shows the partial discharge signals received from the rectangular spiral antenna and the microstrip patch antenna simultaneously. The yellow waveform was measured using the rectangular spiral antenna with a maximum amplitude of $10 \mathrm{mV}$. The red waveform was measured using a microstrip patch antenna with a maximum amplitude of $19 \mathrm{mV}$.

The rectangular spiral antenna is capable of receiving more UHF band energy for its wider band. Thus, it has less catadioptric electromagnetic energy. In this case, the measured signal decreases rapidly and the signal amplitude should also be larger. However, the gain of the designed antenna below $1 \mathrm{GHz}$ is worse than the quasi-TEM horn antenna and the microstrip antenna due to its smaller volume. As a result, the received UHF signal amplitude is relatively low. But it can satisfy the UHF signal detection

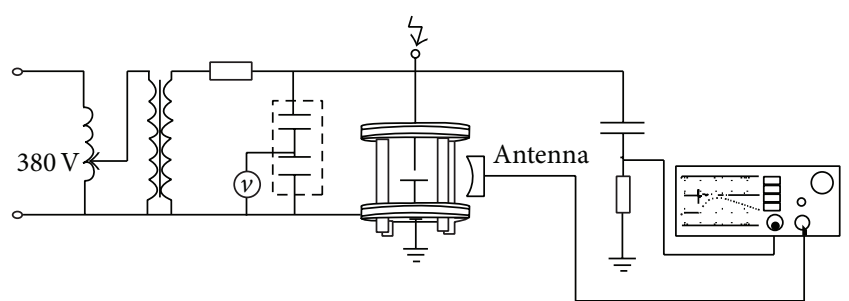

FIGURE 11: Experimental circuit of partial discharge.

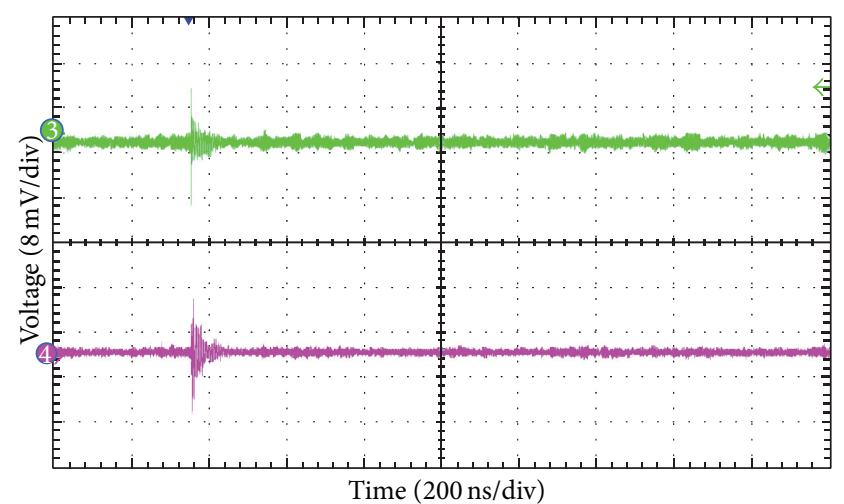

FIGURE 12: UHF signals measured by the rectangular spiral antenna and a quasi-TEM horn antenna.

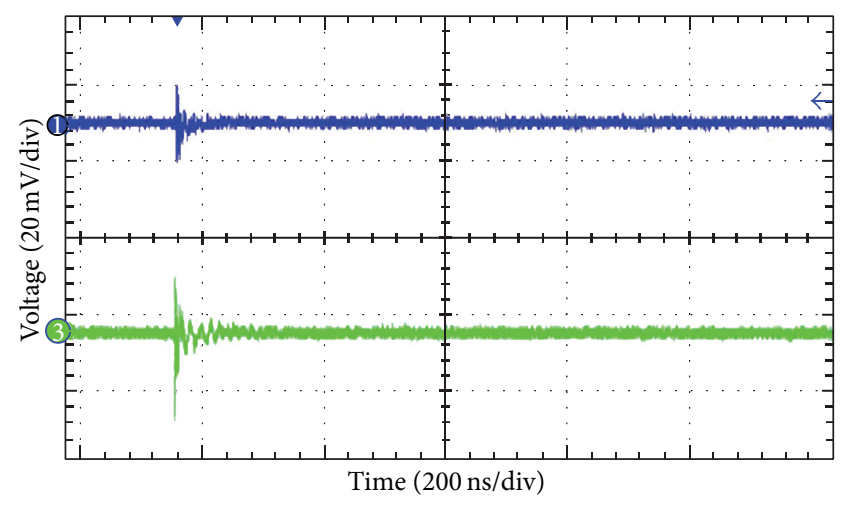

FIGURE 13: UHF signals measured by the rectangular spiral antenna and a microstrip patch antenna.

requirements completely. Moreover, the designed antenna has a wider range frequency band and a bigger gain above $1 \mathrm{GHz}$. If the oscilloscope does not have a bandwidth limit of $1 \mathrm{GHz}$ and can collect signals above $1 \mathrm{GHz}$, the designed antenna will collect a higher signal amplitude compared to the quasi-TEM horn and the microstrip patch antenna.

\section{Conclusions}

The radiation characteristics of the rectangular spiral antenna through simulation and experimental analysis were tested. Furthermore, it was compared with the quasi-TEM horn 
antenna and the microstrip patch antenna in the laboratory. The following conclusions were obtained.

(a) The rectangular spiral antenna is smaller and lighter, which facilities installation and fulfills the miniaturization trends of antennas.

(b) The gain of the designed antenna exhibits a rising trend as the frequency increases in the UHF band. The designed antenna can receive a wider band range of partial discharge signals above $1 \mathrm{GHz}$. The measured bandwidth is $1.15 \mathrm{GHz}-1.55 \mathrm{GHz}, 1.9 \mathrm{GHz}-2.7 \mathrm{GHz}$, and $2.85 \mathrm{GHz}-3 \mathrm{GHz}$. Furthermore, the designed antenna achieves a good oriented reception performance.

(c) The data show that the gain of the designed antenna is slightly inferior to the quasi-TEM horn antenna and the microstrip patch antenna under $1 \mathrm{GHz}$. However, the designed antenna has better broadband. It has a wider frequency band range and a bigger gain above $1 \mathrm{GHz}$ and is capable of detecting the UHF signal generated by partial discharge better.

\section{Conflict of Interests}

The authors declare that there is no conflict of interests regarding the publication of this paper.

\section{Acknowledgments}

The authors gratefully acknowledge the financial support from China National Natural Science Foundation (51277188), Program for China New Century Excellent Talents (NCET12-0590), and Project no. 0213005202042 supported by the Fundamental Research Funds for the Central Universities in China.

\section{References}

[1] G. Bazannery, "Recent developments in insulation monitoring systems of GISs," International Electric Power for China, vol. 6, no. 4, pp. 41-43, 2002.

[2] J. Tang, W. Zhu, and C.-X. Sun, "Analysis of UHF method used in partial discharge detection in GIS," High Voltage Engineering, vol. 29, no. 12, pp. 22-23, 2003.

[3] C.-X. Sun, G.-F. Xu, and J. Tang, "Model and performance of inner sensors used for partial discharge detection in GIS," Proceedings of the Csee, vol. 24, no. 8, pp. 89-94, 2004.

[4] D.-S. Kim, C.-M. Hwang, Y.-N. Kim et al., "Development of an intelligent spacer built into the internal-type UHF partial discharge sensor," in Proceedings of the IEEE International Symposium on Electrical Insulation (ISEI '08), pp. 396-399, Vancouver, Canada, June 2008.

[5] J. Tang, H.-J. Shi, and C.-X. Sun, "Study of UHF frequency response characteristics of the inner sensor for partial discharge detection in GIS," Transactions of China Electrotechnical Society, vol. 19, no. 5, pp. 71-75, 2004.

[6] R. Kurrer and K. Feser, "The application of ultra-high-frequency partial discharge measurements to gas-insulated substations," IEEE Transactions on Power Delivery, vol. 13, no. 3, pp. 777-782, 1998.
[7] X.-X. Zhang, W.-T. Liu, and X.-H. Yang, "A Hilbert fractal antenna and portable monitoring system for partial discharge detection in gas insulated substations," Journal of Chongqing University, vol. 32, no. 3, pp. 263-268, 2009.

[8] C.-P. Kao, J. Li, R. Liu, and Y. Cai, "Design and analysis of UWB TEM horn antenna for ground penetrating radar applications," in Proceedings of the IEEE International Geoscience and Remote Sensing Symposium (IGARSS '08), vol. 4, pp. IV569-IV572, Boston, Mass, USA, July 2008.

[9] Q.-L. Li and G.-B. Xu, "Miniature design of ultra-wideband spiral antenna," Journal of Telemetry, Tracking and Command, vol. 32, no. 2, pp. 14-19, 2011.

[10] X.-Q. Yan and L.-F. Qi, "Study on deforming of planar spiral antenna," Tactical Missile Technology, no. 4, pp. 29-31, 2005.

[11] N.-K. Jing, H.-L. Zhao, and L. Huang, "Miniaturization of broadband spiral antenna," Modern Electronics Technique, vol. 34, no. 17, pp. 82-84, 89, 2011.

[12] J. Kaiser, "The Archimedean two-wire spiral antenna," IRE Transactions on Antennas and Propagation, vol. 8, no. 3, pp. 312323, 1960.

[13] B. A. Kramer, M. Lee, C.-C. Chen, and J. L. Volakis, "Design and performance of an ultrawide-band ceramic-loaded slot spiral," IEEE Transactions on Antennas and Propagation, vol. 53, no. 7, pp. 2193-2199, 2005.

[14] H. Nakano, K. Kikkawa, and J. Yamauchi, "A low-profile equiangular spiral antenna backed by a cavity with an absorbing strip," in Proceedings of the 1st European Conference on Antennas and Propagation (EuCAP '06), pp. 1-5, Nice, France, November 2006.

[15] J.-B. Wu, M. Tain, and T.-Q. Li, "Improvement of bow-tie antenna for ground penetrating radar," Chinese Journal of Scientific Instrument, vol. 30, no. 5, pp. 1059-1062, 2009.

[16] X.-X. Zhang, Y. Chen, J.-Z. Tang, and X.-S. Wen, "Minitype quasi-TEM horn antenna for partial discharge detection in GIS," High Voltage Engineering, vol. 37, no. 8, pp. 1975-1981, 2011.

[17] X.-X. Zhang, J. Tang, and W.-X. Peng, "Study on the outer UHF microstrip patch antenna for partial discharge detection in GIS," Chinese Journal of Scientific Instrument, vol. 27, no. 12, pp. 15951599, 2006. 

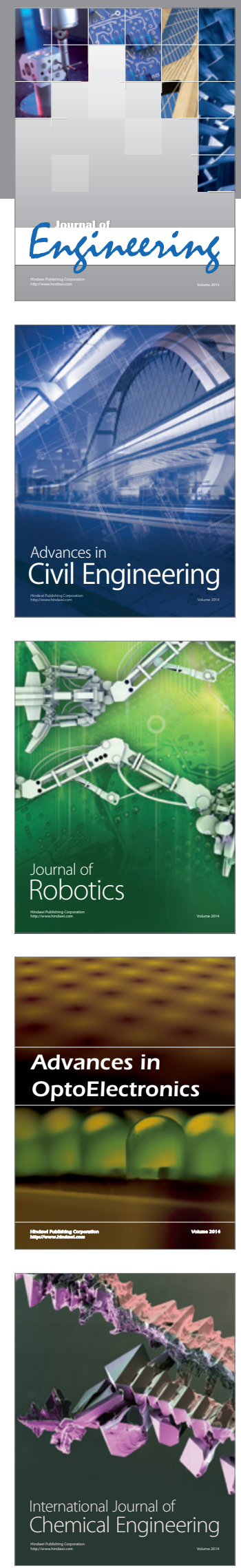

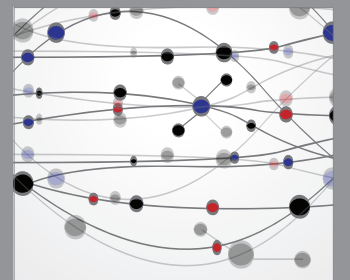

The Scientific World Journal
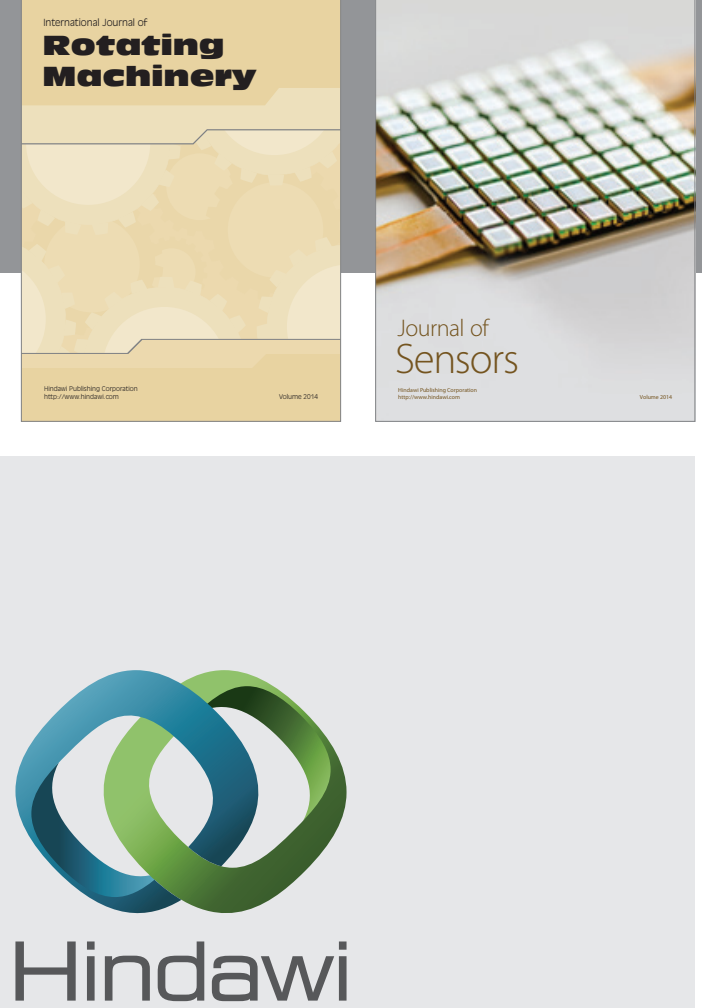

Submit your manuscripts at http://www.hindawi.com
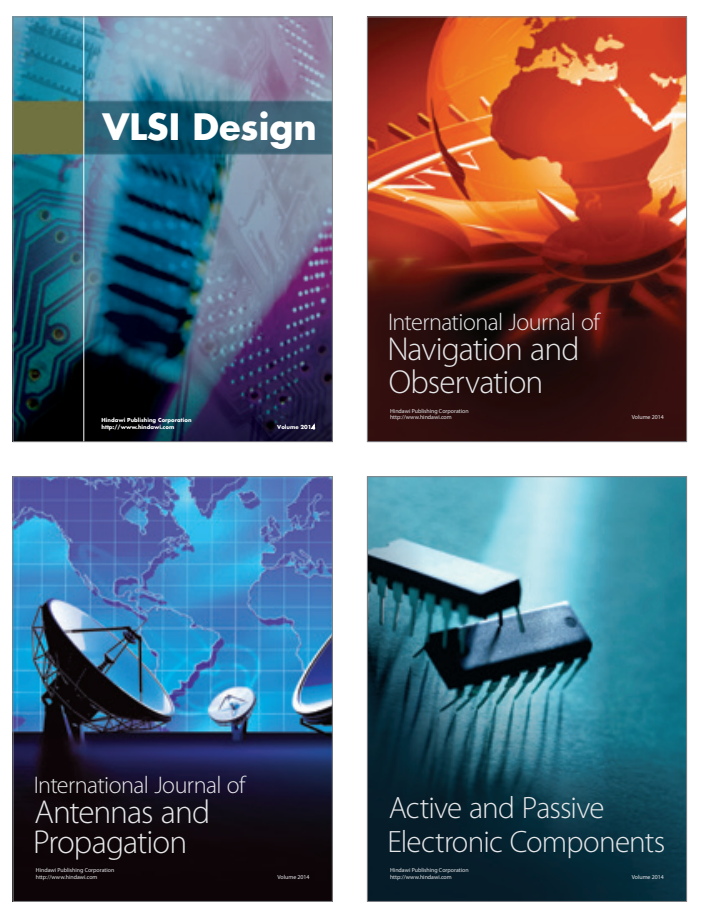
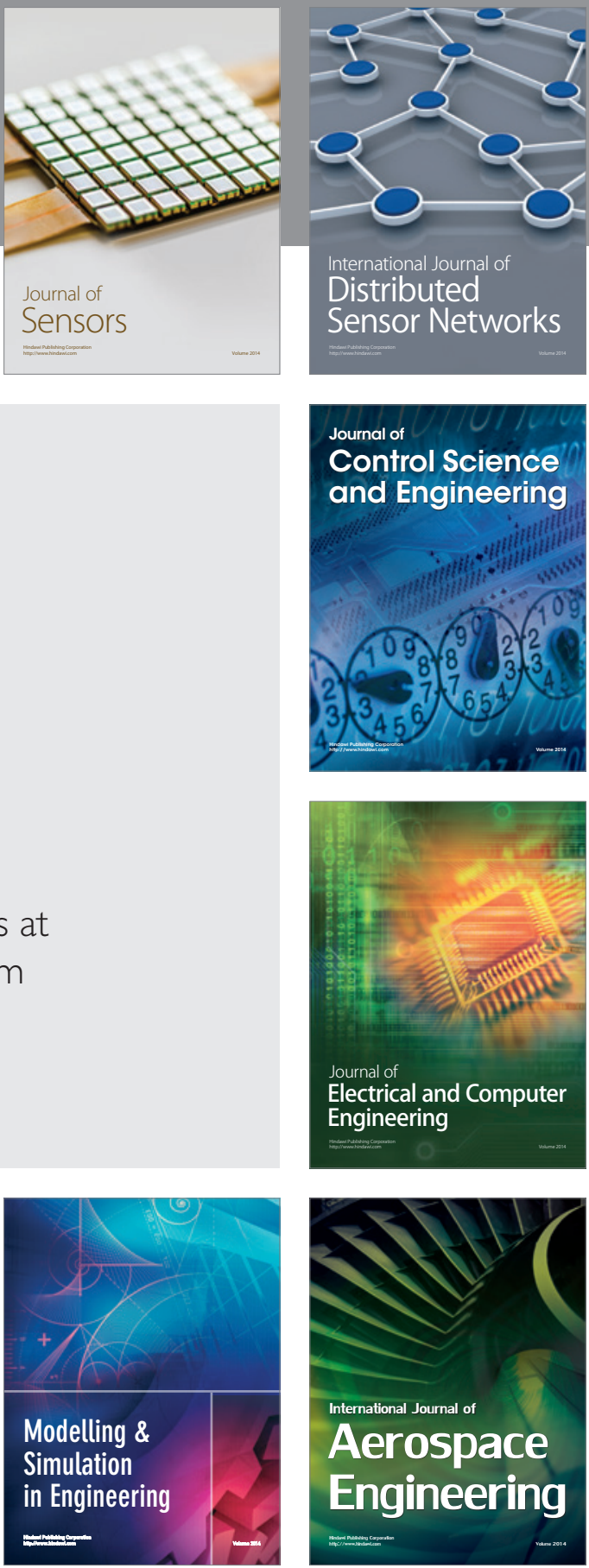

Journal of

Control Science

and Engineering
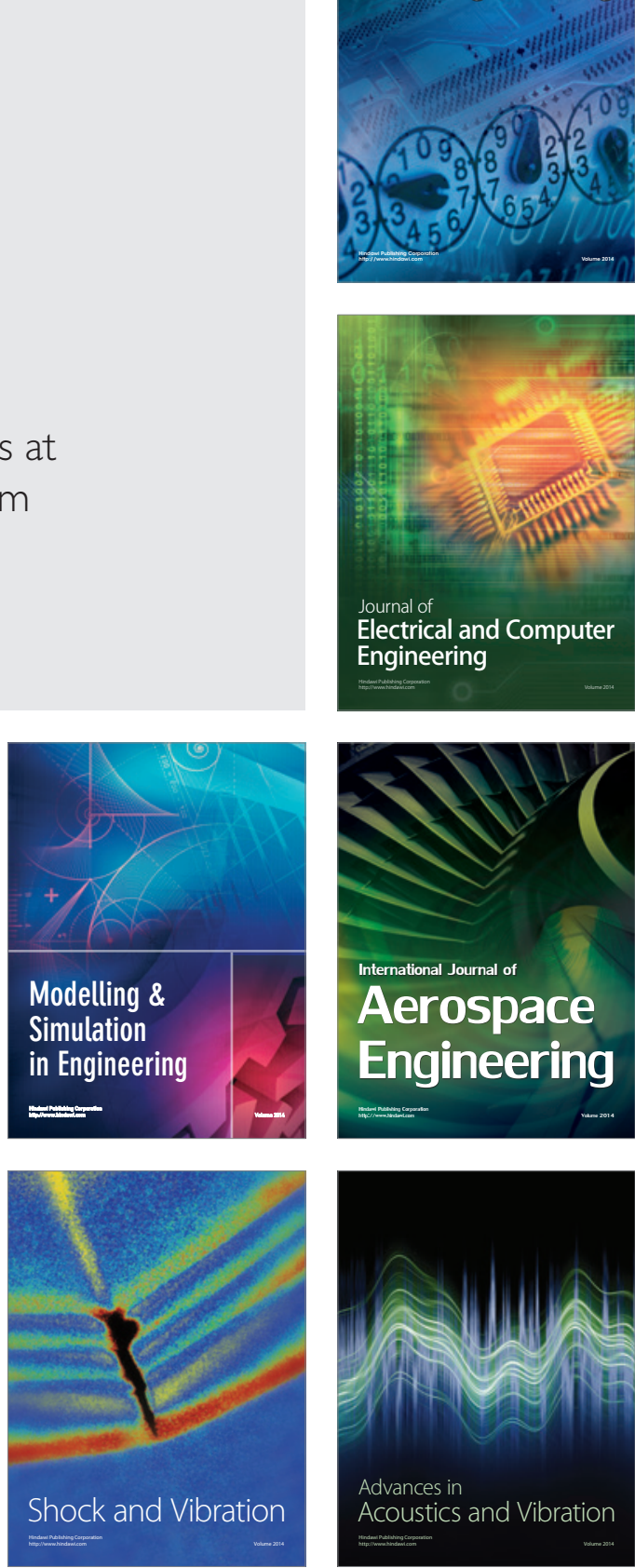